\title{
Immunoglobulin Subclasses in Normal Children
}

\author{
PETER H. SCHUR,"' FRED ROSEN, AND MICHAEL E. NORMAN \\ The Roberi B. Brigham Hospital and Childrens Hospital Medical Center, Harvard Medical School. Boston, and \\ Department of Pediatrics, University of Pennsylvania School of Medicine, Philadelphia, Pennsylvania, USA
}

\begin{abstract}
Summary
The range, mean, and normal bounds of serum IgG 1-4 subclass concentrations in children $0-16$ years old are given. Levels increase with age, plateauing at different ages.

Definition of the normal range will permit better identification of individuals with either low or high levels.

\section{Speculation}

These studies, by defining the range of $\gamma \mathrm{G1}, \gamma \mathrm{G} 2, \gamma \mathrm{G3}$, and $\gamma \mathrm{G4}$ levels in normal individuals, will help further define who is hypogammaglobulinemic.

A considerable body of knowledge has been accumulated regarding the structure, genetics, and biology of the subclasses of human $\operatorname{IgG}(2,4,5,8)$. In addition, through the increasing availability of antisera, levels of these proteins are being measured in patients with various disorders $(2,4,5,8)$. Of particular interest has been the detection of individuals with isolated or multiple deficiencies of these subclasses $(2,3,7,9)$. Deficiency in most of these studies has been defined in terms of the normal adult ranges for these proteins, but few normal children have been studied. To facilitate the recognition of IgG subclass deficiencies in children, we have determined the range of IgG subclass protein levels in normal children of different ages.
\end{abstract}

\section{MATERIALS AND METHODS}

Monospecific antisera to the four IgG subclasses were developed in this laboratory as follows. Rabbits and monkeys were made tolerant to three IgG subclasses and then immunized with isolated myeloma proteins of the other IgG subclass. Antisera were tested by immunoelectrophoresis vs. normal sera to make sure that they only reacted with immunoglobulins. Antisera were tested by radial immunodiffusion against myeloma proteins of $\operatorname{IgA}, \operatorname{IgM}, \operatorname{IgD}$, IgE, and all four IgG subclasses. Antisera were absorbed as necessary until specific by radial immunodiffusion.

Levels of the four IgG subclasses in serum were determined by radial immunodiffusion using these monospecific antisera. Six myeloma proteins of each subclass, of both $x$ and $\lambda$ types served as standards. World Health Organization teference serum 67/95 gave values of: IgG1, $7.1 \mathrm{mg} / \mathrm{ml} ; \mathrm{IgG2}, 2.1 \mathrm{mg} / \mathrm{ml} ; \mathrm{IgG} 3,0.7 \mathrm{mg} /$ $\mathrm{ml}$; and $\mathrm{IgG} 4,0.56 \mathrm{mg} / \mathrm{ml}$.

Geometric means of immunoglobulin concentrations for each age group were calculated from the logarithm of the values (I). The normal bounds of each subclass for each age group was calculated by taking the logarithm of each value, and calculating the mean \pm twice the SD of the logarithms and then taking the antilogs of the results (1).

\section{RESULTS}

Sera from 281 children 6-191 months old were analyzed, including 22 children $6-11$ months old, 42 children 12-23 months old, 36 children 24-35 months old, 52 children 36-47 months old, 31 children 48-71 months old, 24 children $72-95$ months old, 21 children 96-119 months old, 33 children $120-155$ months old, and 19 children $156-191$ months old.

The results of $\mathrm{IgG}$ subclass determinations on individual sera are depicted in Figure 1 , in addition to the geometric means thereof. The geometric mean and the normal bounds are given in Table I. Mean IgGi levels gradually increase with age, reaching adult plateau at about 96-120 monihs of age. There is a considerable range for each age group, but levels below $2 \mathrm{mg} / \mathrm{ml}$ can be considered to be subnormal. Mean IgG2 levels also increase with age, reaching adult levels at about 192 months of age. There is also a considerable spread of normal values in each age range; the lowest level seen was $0.24 \mathrm{mg} / \mathrm{ml}$. Mean IgG3 levels did not vary much with age, being about $0.3 \mathrm{mg} / \mathrm{ml}$ at about 6 months and about $0.5 \mathrm{mg} / \mathrm{ml}$ at adulthood. The range on the other hand tended to be smaller in children of a young age as compared to. adolescents. The lowest level seen was $0.08 \mathrm{mg} / \mathrm{ml}$. Mean IgG4 levels increased with age, reaching the adult plateau at about $96-$ 120 months. The range of values tended to be small for the first 18 months; subsequently it increased and was considerable. Undetectable levels, i.e., less than about $0.04 \mathrm{mg} / \mathrm{ml}$, were seen in 10 sera in children from early childhood through adolescence.

\section{DISCUSSION}

IgG subclass proteins can be detected as early as 11 weeks in the fetus (6). By about 33 weeks, levels in the fetus are very similar to those in the mother (3). However, at gestation, levels of IgG I tend to be somewhat higher in the mother than in the newborn, while levels of IgG2, IgG3, and IgG4 are rather similar $(3,6)$. Levels then fall in the newborn, with IgG3 levels reaching their nadir at about I month, IgGI and IgG2 at 3 months, and IgG4 at about 4 months. Yount et al. (9) examined the sera of 10 infants 3-9 months old and the sera of 6 normal children $11 / 2-5$ years old in his study of hypogammaglobulinemia. Morell et al. (3) analyzed 95 sera from children (clinical status not stated) between 0 and 2 years old. They stated that at 2 years of age, mean IgG 1 and IgG3 levels were not far from adult values, whereas mean $\mathrm{IgG} 2$ and IgG4 levels were only one-half of adult values. Our present observations are similar, except that we found that mean IgGI levels did not get to adult levels until about 8-10 years of age. Analysis of means fails to appreciate the range of values of the different subclasses at different ages. Although there seems to be a fairly direct correlation between increasing age and levels of IgG1, IgG2, and IgG4 this did not appear to be the case for IgG3. Whether the restricted range of $\mathrm{IgG} 3$ represents lack of a response to limited antigen exposure, or simply the lack of IgG3 response is not clear.

Another facet of these data concerns the definition of hypogammaglobulinemia. The levels in milligrams per milliliter (or equivalent) at which this is defined varies somewhat with age. As far as levels of the IgG subclasses are concerned, the lower limit of the normal range did not vary much with age being approximately $2 \mathrm{mg} / \mathrm{ml}$ for IgGl, $0.24 \mathrm{mg} / \mathrm{ml}$ for $I g G 2,0.3 \mathrm{mg} / \mathrm{ml}$ for $\mathrm{IgG3}$, and $0.04 \mathrm{mg} / \mathrm{ml}$ for IgG4. 

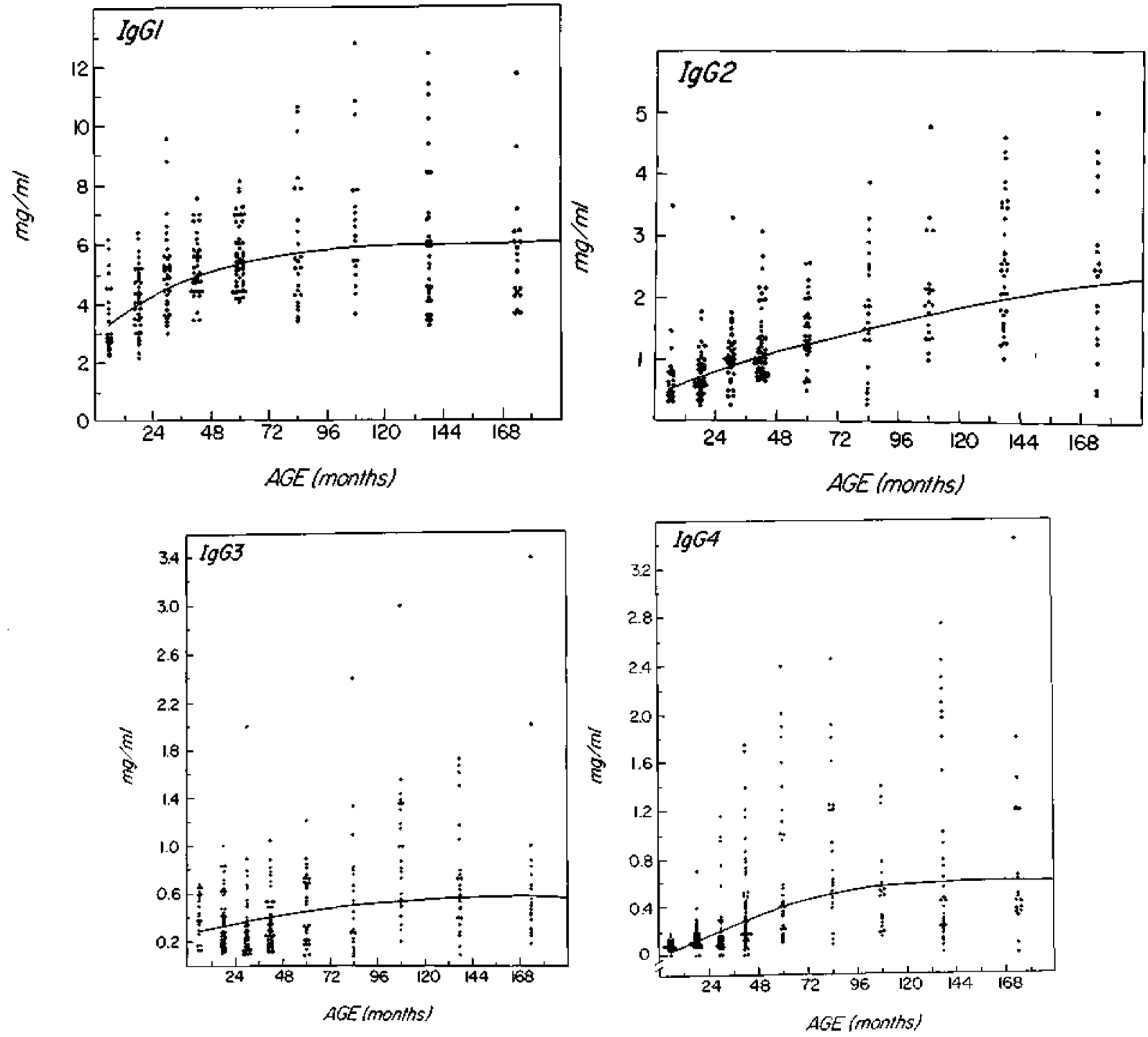

Fig. 1. The serum concentration of each IgG subclass in individual sera is depicted for children of different ages. The line represents a smoothed out curve through the geometric means at each age.

Table 1. Serum immunoglobulin levels $(\mathrm{mg} / \mathrm{ml})^{1}$

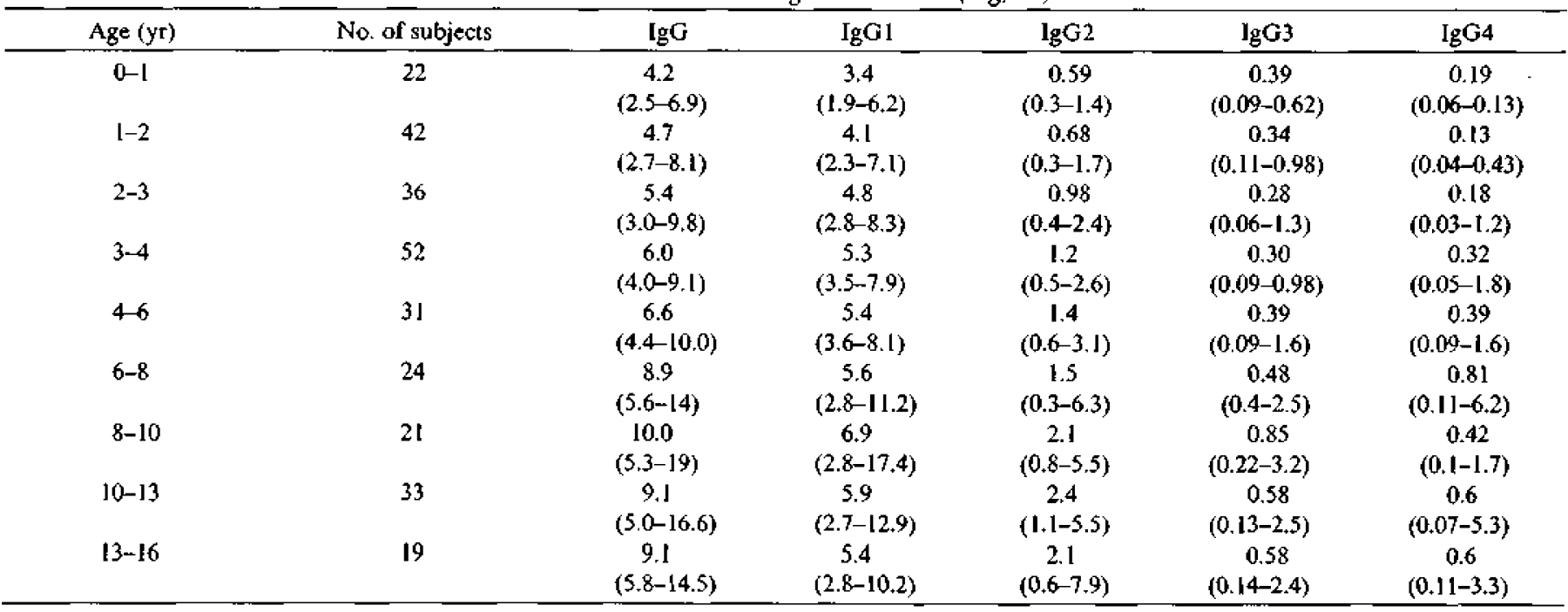

${ }^{1}$ Geometric means are presented for each Ig at every age. The normal bounds, given in parentheses, are obtained by taking the mean logarithm \pm twice the SD of the logarithms and then taking the antilogs of the results. 